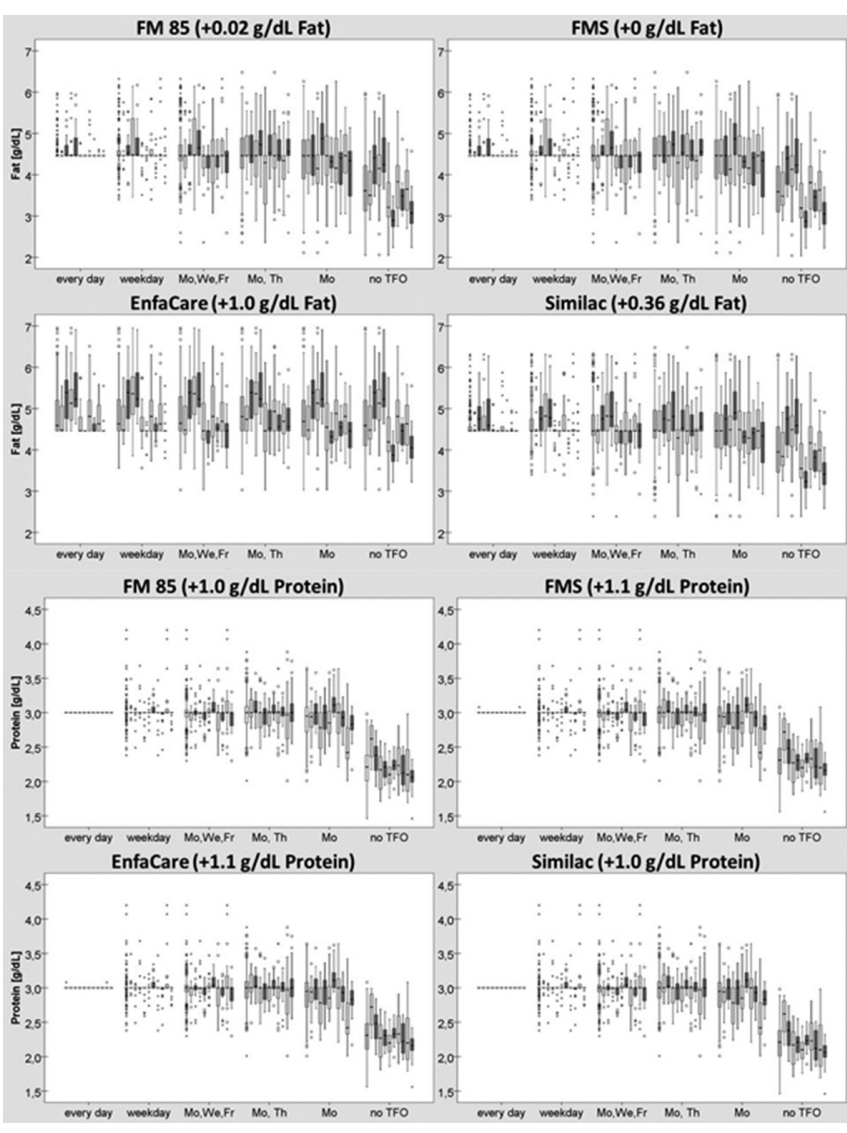

Abstract 0-122 Figure 1

Background TFO of breast milk (BM) overcomes the uncertainty of macronutrient intake in fixed dose fortification (FDF) resulting from natural variation in breast milk and improves growth of VLBW infants.

Objective To study variation of macronutrient intake and energy ratios when TFO is done using four different milk fortifiers and based on various frequencies of milk measurements.

Study design Ten infants, GA: $26.1 \pm 1.3$ wks, BW: $890 \pm 210$ g. Daily measurements $(\mathrm{n}=210$ ) of native BM's fat, protein (NIR milk analyzer), and lactose (UPLC-MS/MS) levels provided the basis for model calculation to add fat, protein and carbohydrates using modular products after FDF with either FM85, FMS, Enfamil, or Similac to meet ESPGHAN recommendations. $\mathrm{BM}$ measurement frequencies were $7 / \mathrm{wk}, 5 / \mathrm{wk}, 3 / \mathrm{wk}, 2 / \mathrm{wk}, 1 /$ wk, and 0/wk (only FDF).

Results Measurement 2/wk increased mean macronutrient intake and day-to-day variation was not higher compared to native BM. Day-to-day variation decreased with increasing frequency of milk analysis (Fig). After adding FDF mean carbohydrate level already exceeded in 3 fortifiers and median fat level in 1 fortifier leading to higher calorie intake than target levels.

TFO 7/wk achieved macronutrient levels close to target when routine fortifier was composed with $1.1 \mathrm{~g}$ protein/dL (no fat, no $\mathrm{CHO}$ ) whereas for measurements $1-2 / \mathrm{wk}$, it was achieved with composition of fat $0.4 \mathrm{~g} / \mathrm{dL}$, protein $1.2 \mathrm{~g} / \mathrm{dL}$ and carbohydrate $1.1 \mathrm{~g} / \mathrm{dL}$.

Conclusions Measurements of macronutrient 1-2/wks might provide a reasonable balance between workload and clinical outcome. Due to different composition of fortifiers, either target values for macronutrients or composition of fortifier for use with TFO needs to be reconsidered in order to achieve recommended intake.

\section{0-123 INTAKES OF MICRONUTRIENTS IS ASSOCIATED WITH EARLY GROWTH IN EXTREMELY PRETERM INFANTS - A POPULATION-BASED STUDY}

${ }^{1}$ E Stoltz Sjöström, ${ }^{1}$ Öhlund, ${ }^{2} \mathrm{~F}$ Ahlsson, ${ }^{1} \mathrm{M}$ Domellöf. ${ }^{1} \mathrm{Clinical}$ Sciences Pediatrics, Umeå University, Umeå, Sweden; 'Women's and Children's Health, Uppsala University, Uppsala, Sweden

\subsection{6/archdischild-2014-307384.190}

Background Extremely preterm infants have high nutrient requirements due to limited stores of nutrients and rapid postnatal growth. However, many infants experience suboptimal growth. It is still unclear to what extent micronutrient intakes affect growth during early postnatal life in these infants.

Aim To describe micronutrient intakes and explore possible associations with growth during the first 70 days of life in extremely preterm infants.

Methods Retrospective population-based study including extremely preterm infants $(<27$ weeks) born in Sweden during 2004-2007. Detailed nutritional and growth data were derived from hospital records.

Results Included infants $(\mathrm{n}=531)$, had a mean gestational age of 25 weeks+2 days and a mean birth weight of 765 g. Intakes of calcium, phosphorus magnesium, zinc, copper, iodine, vitamin $\mathrm{D}$ and folate were lower than estimated requirements while intakes of iron, vitamin $\mathrm{K}$ and several water-soluble vitamins were higher than estimated requirements. High iron intakes were explained by blood transfusions. Taking macronutrient intakes and severity of illness into account, folate intakes were positively correlated with weight $(\mathrm{p}=0.001)$ and length gain $(\mathrm{p}$ $=0.003)$ and iron intake was negatively associated with length gain $(\mathrm{p}=0.006)$ during the first 70 days of life.

Conclusions Intakes of many micronutrients were insufficient. Even when considering macronutrient intakes and severity of illness, several micronutrients were independent predictors of early growth. Low intakes of folate were associated with poor weight and length gain and high iron intakes were associated with poor length and head circumference growth. Optimised early micronutrient intakes may improve early growth in extremely preterm infants.

\section{0-124 HUMAN MILK CREAM ENHANCES GROWTH WHEN SUPPLEMENTING STANDARD FORTIFICATION OF AN EXCLUSIVE HUMAN MILK-BASED DIET IN VLBW INFANTS}

${ }^{1} \mathrm{AB}$ Hair, ${ }^{2} \mathrm{CL}$ Blanco, ${ }^{1} \mathrm{KM}$ Hawthorne, ${ }^{2} \mathrm{AG}$ Moreira, ${ }^{3} \mathrm{ML}$ Lee, ${ }^{4} \mathrm{DJ}$ Rechtman, ${ }^{1} \mathrm{SA}$ Abrams. ${ }^{1}$ Pediatrics, Baylor College of Medicine USDA/ARS Children's Nutrition Research Center, Houston Texas, USA; ${ }^{2}$ Pediatrics, University of Texas Health Science Center, San Antonio Texas, USA; ${ }^{3}$ Research and Development, Prolacta Bioscience, Industry California, USA; ${ }^{4}$ Medical Affairs, Prolacta Bioscience, Industry California, USA

\subsection{6/archdischild-2014-307384.191}

Background The use of an exclusively human milk (HM)-based diet lowers the incidence of NEC, however concerns exist regarding adequate growth. Frequently, donor and maternal HM have a low caloric content. A HM cream -derived supplement can increase the caloric density of an exclusive HM-based diet.

Objective Determine if premature infants fed an exclusive HMbased diet and a HM cream-derived supplement (Cream) would have equal growth compared to infants fed a standard feeding regimen (Control). 